\title{
Peltier modules in cooling systems for electronic components
}

\author{
K. Domke \& P. Skrzypczak \\ Poznan University of Technology, \\ Institute of Electrical Engineering and Electronics, Poland
}

\begin{abstract}
Currently used electronic components (LED, processors, CCD matrices) are distinct for their increasingly dense packing of active elements and, consequently, higher heat loss power per a single element. The arising thermal barrier restricts the functionality and further development of components in their present-day form. Cooling systems (natural or forced types, including water cooling systems) sometimes fail to come up to the required standard. The paper discusses a concept whereby the operation of standard cooling systems is supported by incorporation of Peltier elements. A heat flow analysis is presented for systems containing: an electronic element - Peltier element - radiator, complete with a study of cooling efficiency and elements facilitating the process of design of such combined systems. Also, experimental data from tests examining the process of cooling in sample systems will be provided.
\end{abstract}

Keywords: Peltier module, LED cooling system, heat transfer.

\section{Introduction}

Early cooling systems for electronic elements incorporated a radiator as the basic element ensuring proper heat dissipation from the system. The radiator's parameters (material type, size of heat radiating surfaces and their mutual spatial arrangement) determined thermal resistance of the system and, therefore, the efficiency of cooling. An increased number of elements per area unit, together with a higher clock rate, increased thermal power which had to be directed away from a single system. Forced air circulation (forced convection) makes it possible to considerably reduce thermal resistance of the cooling system, however does not allow for reducing $R_{\text {thrad-amb }}$ below zero. As a result, the 
temperature of the exterior part of the electronic element housing is always higher than the temperature of the surroundings. Incorporation of a Peltier module in the system helps to overcome this barrier and, from the theoretical viewpoint, obtain thermal resistance levels below zero and the temperature of the electronic element surface that is lower than ambient temperature.

\section{Peltier module: principle of operation}

The principle of operations of the Peltier module is based on the Peltier effect which consists of heat energy transfer in response to the applied voltage. Thermal energy flows between two sides of the module: cold and hot. Consequently, the module absorbs heat from an element (e.g. LED) touching the cold side and gives it away to another element in the system (e.g. radiator) which is in contact with the hot side. The configuration of a single-stage Peltier module is shown below (Fig. 1).

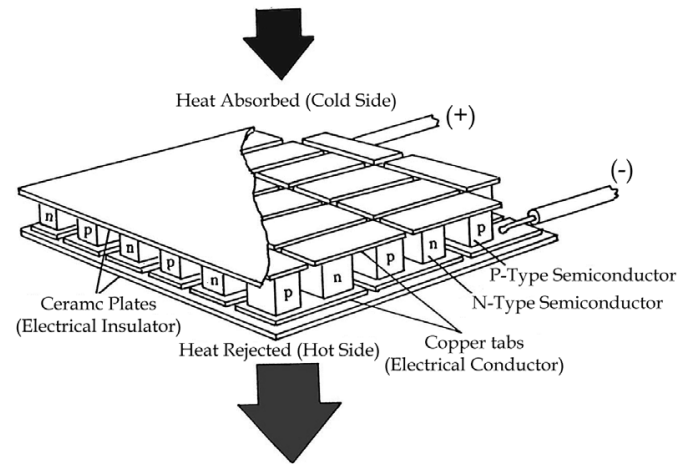

Figure 1: $\quad$ Single-stage Peltier module configuration [1].

Typical parameters of Peltier module include: maximum supply current and voltage $\left(I_{P l t \text {-max }}, U_{P l t \text {-max }}\right)$, maximum obtainable difference in temperature between the sides $\left(\Delta T_{P l t-m a x}\right)$, maximum thermal power transferred from the cold to the hot side $\left(Q_{c-\max }\right)$. All these parameters depend on the material from which columns are made, the number of columns $N$, their height $h$ and cross-sectional area $A$, as well as properties of $p-n$ and ceramic elements. Due to optimum parameters demonstrated in the $(-100 \div+200)^{\circ} \mathrm{C}$ temperature range, the material most frequently used for module construction is bismuth telluride $\mathrm{Bi}_{2} \mathrm{Te}_{3}$, whose properties are accounted for in detail in literature [1-3]. Bismuth telluride has the highest figure of merit (Z) [1] defined according to the relation given in (1), presented for various materials in Fig. 2.

$$
Z=\frac{\alpha^{2}}{\rho \cdot \lambda}
$$


where $\alpha$-Seebeck coefficient of columns, $\rho$ - electrical resistivity, $\lambda$ - specific thermal conductivity of the material from which columns in the Peltier module are made.

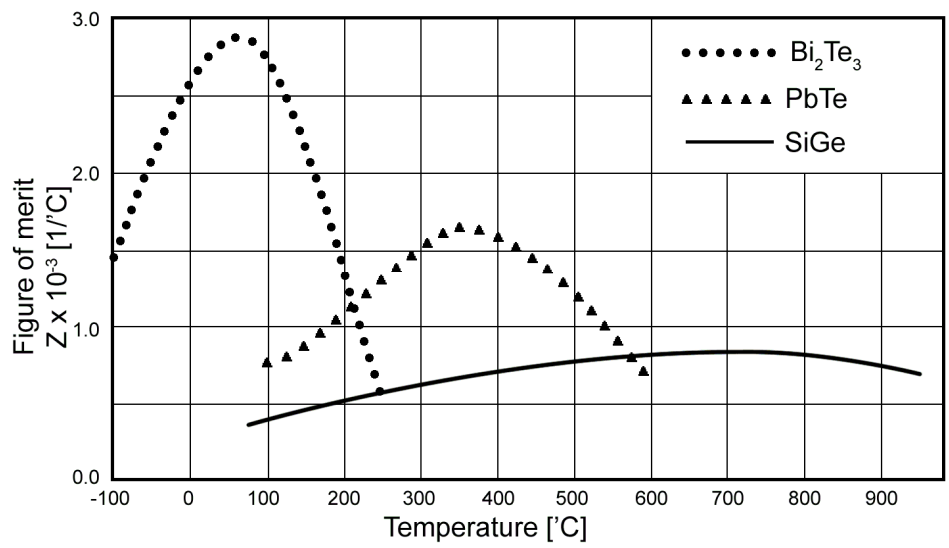

Figure 2: $\quad$ Typical figure of merit $(Z)$ for several TE Materials [4].

For the material demonstrating the highest figure of merit $\left(\mathrm{Bi}_{2} \mathrm{Te}_{3}\right)$, three parameters defining module operation were determined: Seebeck coefficient $-S$, electrical resistance of the module $-R_{e l}$ and thermal resistance of the module $R_{t h, \lambda}$. The relationship between value these parameters and the mean value of average module temperature $t_{a v, P l t}$ and $G F$ values defining geometric dimensions of the columns and their amount $N$ in the module is defined by formulas given below (2) [5]:

$$
\begin{aligned}
S & =2 \cdot N \cdot f_{S}\left(t_{a v, P l t}\right)=2 \cdot N \cdot\left(202,46+0,40232 \cdot t_{a v}-0,0027687 \cdot t_{a v}^{2}\right) \cdot 10^{-6} \\
R_{e l} & =\frac{2 \cdot N}{G F} f_{R}\left(t_{a v, P l t}\right)=\frac{2 \cdot N}{G F}\left(10,169+0.049056 \cdot t_{a v}+0,0000395 \cdot t_{a v}^{2}\right) \cdot 10^{-6} \\
R_{t h, \lambda} & =\frac{1}{2 \cdot N \cdot G F} \cdot f_{\lambda}\left(t_{a v, P l t}\right)=\frac{1}{2 \cdot N \cdot G F} \cdot\left[\left(1613,8+2,3413 \cdot t_{a v}+0,06455 \cdot t_{a v}^{2}\right) \cdot 10^{-3}\right]^{-1}
\end{aligned}
$$

where $G F$ represents the ratio of the cross-sectional area of a single column to the height of the column.

The quantities give a direct indication of:

- the module's heat transfer capacity: $S\left(T_{h}-T_{c}\right) I_{P l t}$

- the module's heat loss power: $\left(R_{e l} \cdot I_{P l t}^{2}\right)$ 
- the module's thermal conduction power: $\frac{\left(T_{h}-T_{c}\right)}{R_{t h, \lambda}}$

Despite high interest in Peltier modules, doping of materials used for their construction and introduction of new module structures [1,3], the problem of appropriate selection of module parameters in "cooled element - Peltier module - radiator" type systems, which would ensure the lowest possible temperature of the element being cooled, has not been addressed in sufficient detail as yet. Studies in this area have been conducted in the Poznań University of Technology $[5,6]$. Preliminary results indicate that it is necessary to optimize the entire thermal system simultaneously, i.e. adjust the quantities and operating parameters of the module in a way that takes into account thermal parameters of the cooled object, the Peltier module and the radiator.

\section{Thermal system and its model}

The tested module incorporates a high-power LED as the cooled element. The choice was dictated by the fact that photometric parameters of LEDs (e.g. luminous flux $\Phi$ ) have a strong correlation with the LED's $p$ - $n$ junction temperature [7]

$$
\Phi=\Phi_{300} \exp \left(-\frac{T_{j}-300}{T_{o}}\right)
$$

where $\Phi_{300}$ represents luminous flux for the temperature $300 \mathrm{~K}$, while $T_{0}$ is a quantity specific to a given LED type (e.g. LED red $T_{0}=95 \mathrm{~K}$; LED green $T_{0}=295 \mathrm{~K}$; LED blue $\left.T_{0}=1600 \mathrm{~K}\right)$.

To obtain higher luminous flux and higher photometric efficiency, the lowest temperature $T_{j}$ [7] should be pursued. At the same time, LEDs produce a considerable amount of heat which must be dissipated into the environment. The power is defined with the formula:

$$
P_{\text {thLed }}=P \cdot\left(1-\eta_{e}\right)
$$

where $P$ stands for the LED's nominal power and $\eta_{e}-$ its efficiency.

Consequently, LEDs are electronic components in which cooling has a very beneficial effect on functional parameters, increasing luminous flux (and thus improving luminous efficacy), enhancing durability and slowing down ageing. The thermal system tested is composed of a cooled element (HP LED) generating thermal power $P_{\text {thLed }}$, a Peltier module generating thermal power $P_{\text {thPlt }}$ and, at the same time, delivering both powers to the radiator which dissipates them into the surroundings. The configuration of the system is shown in Fig. 3.

The actual cooling system presented in Fig. 3 corresponds to the diagram of thermal resistances illustrating the flow of thermal power in the system, shown in Fig. 4. The diagram represents thermal resistances $R_{t h}$ of elements of the system, thermal powers $P_{\text {th }}$ generated in the cooled LED and the Peltier module, as well as current sources, demonstrating the heat-pumping properties of the Peltier 


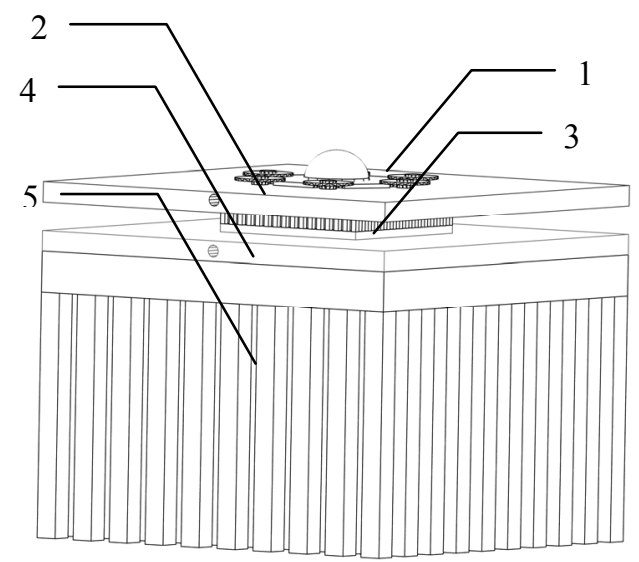

1. HP LED

2. measuring surface of the cold side

3. Peltier module

4. measuring surface of the hot side

5. radiator

Figure 3: Configuration of a LED cooling system with Peltier module and radiator.

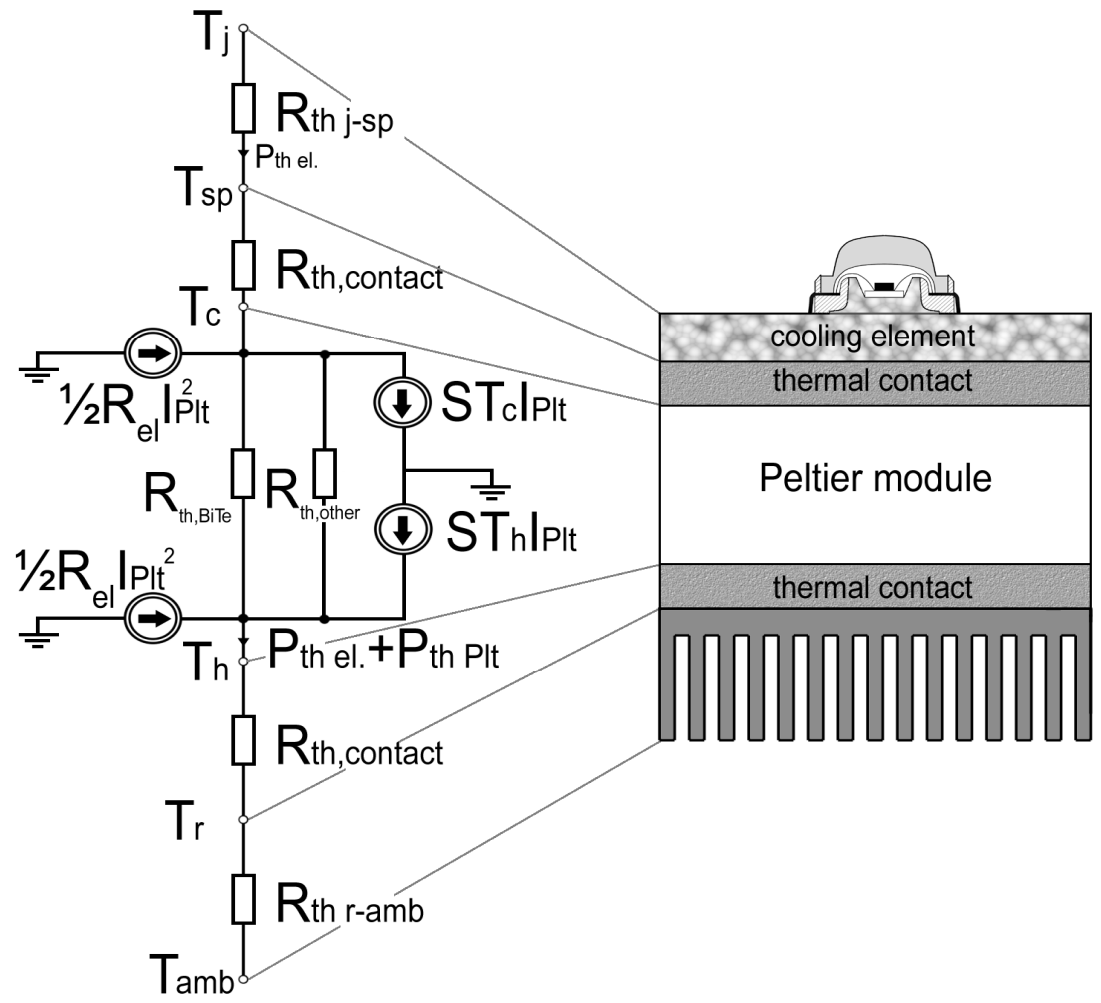

Figure 4: Diagram of heat resistance connections in the tested system. 
module. This makes it possible to determine the values of temperature $T$ of selected points within the thermal circuit, corresponding to the temperature of relevant sections of the actual system.

The diagram was used as a basis for numerical simulation representing the flow of thermal power in systems with LEDs of different power ratings, for different Peltier modules and radiators of different thermal parameters. Thermal resistance and power levels shown in Fig. 4 were determined on the basis of data given in section 4. Results of numerical simulations are illustrated in Fig. 6 and Fig. 7.

\section{Test stand and experimental verification of simulation results}

The test stand was a system with the following structure: LED - Peltier module radiator, along with a set of thermocouples, a programmable power supply, a temperature recorder and a computer controlling the measurements (cf. Fig. 5).

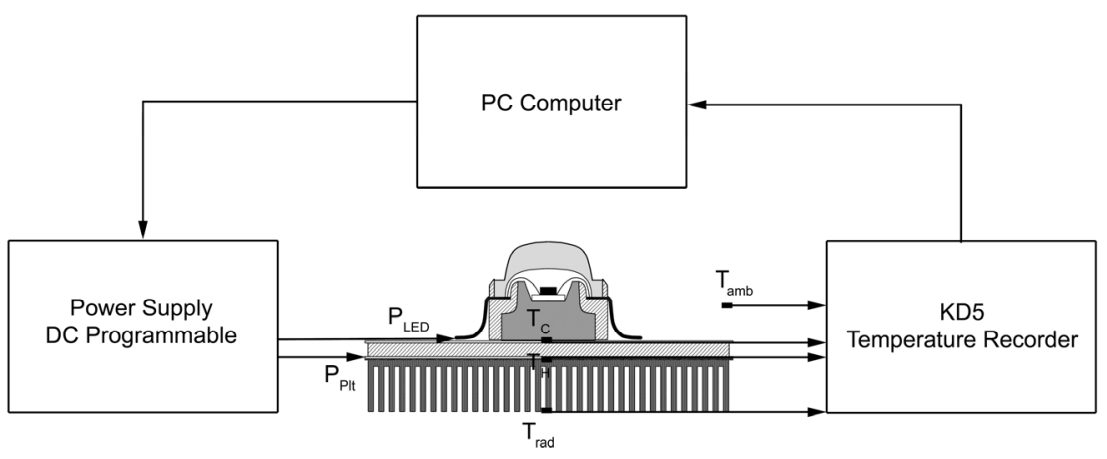

Figure 5: $\quad$ Structure of the power and measurement supply.

Two Peltier modules of different size and power rating were tested:

- $\quad$ TEC-20-31-22 (17.4W); dimensions: 20x20x3.3mm; number of columns $N=31$; column size $2 \times 2 \times 2.2 \mathrm{~mm}$ and the following thermal and electrical characteristics: $\quad Q_{\text {cmax }}=17.4 \mathrm{~W} ; \quad I_{\max }=8 \mathrm{~A}$; $U_{\max }=3.75 \mathrm{~V} ; R_{e l}=0.33 \Omega$;

- TEC-20-127-22 (88.9W); dimensions: 40x40x3.3mm; number of columns $N=127$; column size $2 \times 2 \times 2.2 \mathrm{~mm}$ and the following thermal and electrical characteristics: $Q_{c \max }=88.9 \mathrm{~W} ; \quad \operatorname{Imax}=10 \mathrm{~A}$; $U_{\max }=15.4 \mathrm{~V} ; R_{e l}=1.08 \Omega$.

Additional thermal and electrical quantities adopted for measurements and simulations were: $R_{\text {th, contact }}=0.3 \mathrm{~K} / \mathrm{W}, R_{\text {thrad-amb }}=\mathrm{f}\left(P_{\text {thPlt }}, P_{\text {thLed }}\right)=(6 \div 11) \mathrm{K} / \mathrm{W}$.

For numerical calculations, ambient temperature was adopted as $T_{a m b}=25^{\circ} \mathrm{C}$; while in experimental conditions temperature was measured directly, with actual values taken into account in the processing of results. 
Table 1: $\quad$ Results of measurements for LED power losses $P_{\text {thLed }}=1 \mathrm{~W}$.

\begin{tabular}{|c|c|c|c|c|c|c|c|c|c|}
\hline \multicolumn{5}{|c|}{ TEC-20-31-22 } & \multicolumn{5}{|c|}{ TEC-20-127-22 } \\
\hline $\mathrm{P}_{\mathrm{Plt}}$ & $\mathrm{T}_{\mathrm{amb}}$ & $\mathrm{T}_{\mathrm{rad}}$ & $\mathrm{T}_{\mathrm{h}}$ & $\mathrm{T}_{\mathrm{c}}$ & $\mathrm{P}_{\mathrm{Plt}}$ & $\mathrm{T}_{\mathrm{amb}}$ & $\mathrm{T}_{\mathrm{rad}}$ & $\mathrm{T}_{\mathrm{h}}$ & $\mathrm{T}_{\mathrm{c}}$ \\
\hline $\mathrm{W}$ & ${ }^{\circ} \mathrm{C}$ & ${ }^{\circ} \mathrm{C}$ & ${ }^{\circ} \mathrm{C}$ & ${ }^{\circ} \mathrm{C}$ & $\mathrm{W}$ & ${ }^{\circ} \mathrm{C}$ & ${ }^{\circ} \mathrm{C}$ & ${ }^{\circ} \mathrm{C}$ & ${ }^{\circ} \mathrm{C}$ \\
\hline 0.00 & 23.96 & 32.77 & 33.48 & 36.18 & 0.00 & 23.24 & 34.17 & 35.84 & 37.64 \\
\hline 0.05 & 23.94 & 33.81 & 34.66 & 34.26 & 0.13 & 23.23 & 35.08 & 36.92 & 35.42 \\
\hline 0.20 & 23.91 & 35.35 & 36.39 & 33.01 & 0.49 & 23.22 & 37.76 & 40.14 & 35.45 \\
\hline 0.43 & 23.90 & 37.28 & 38.58 & 32.27 & 1.06 & 23.22 & 41.81 & 44.88 & 37.15 \\
\hline 0.74 & 23.90 & 39.42 & 40.99 & 32.04 & 1.82 & 23.23 & 46.63 & 50.63 & 40.07 \\
\hline 1.03 & 23.92 & 41.76 & 43.63 & 32.20 & 2.76 & 23.25 & 52.04 & 57.08 & 43.90 \\
\hline 1.52 & 23.92 & 45.53 & 47.87 & 32.97 & 3.86 & 23.28 & 58.17 & 64.33 & 48.56 \\
\hline 2.10 & 23.94 & 48.96 & 51.93 & 33.92 & 5.08 & 23.31 & 64.36 & 71.76 & 53.73 \\
\hline 2.81 & 23.94 & 52.35 & 55.75 & 35.39 & 6.47 & 23.35 & 71.12 & 79.84 & 59.56 \\
\hline 3.62 & 23.97 & 57.41 & 61.64 & 37.80 & 7.93 & 23.38 & 78.17 & 88.27 & 66.08 \\
\hline 4.39 & 23.99 & 62.14 & 67.16 & 40.31 & 9.50 & 23.42 & 85.31 & 96.88 & 72.96 \\
\hline 5.40 & 24.02 & 66.91 & 72.69 & 43.44 & 11.14 & 23.44 & 92.11 & 104.00 & 79.76 \\
\hline 6.42 & 24.04 & 71.19 & 77.70 & 46.45 & 12.90 & 23.47 & 99.62 & 112.00 & 87.58 \\
\hline 7.36 & 24.07 & 76.02 & 83.42 & 50.05 & & & & & \\
\hline 8.45 & 24.07 & 80.00 & 88.19 & 53.45 & & & & & \\
\hline
\end{tabular}

Table 2: $\quad$ Results of measurements for the LED power loss $P_{\text {thLed }}=2.73 \mathrm{~W}$.

\begin{tabular}{|c|c|c|c|c|c|c|c|c|c|}
\hline \multicolumn{5}{|c|}{ TEC-20-31-22 } & \multicolumn{5}{|c|}{ TEC-20-127-22 } \\
\hline $\mathrm{P}_{\mathrm{Plt}}$ & $\mathrm{T}_{\mathrm{amb}}$ & $\mathrm{T}_{\mathrm{rad}}$ & $\mathrm{T}_{\mathrm{h}}$ & $\mathrm{T}_{\mathrm{c}}$ & $\mathrm{P}_{\mathrm{Plt}}$ & $\mathrm{T}_{\mathrm{amb}}$ & $\mathrm{T}_{\mathrm{rad}}$ & $\mathrm{T}_{\mathrm{h}}$ & $\mathrm{T}_{\mathrm{c}}$ \\
\hline $\mathrm{W}$ & ${ }^{\circ} \mathrm{C}$ & ${ }^{\circ} \mathrm{C}$ & ${ }^{\circ} \mathrm{C}$ & ${ }^{\circ} \mathrm{C}$ & $\mathrm{W}$ & ${ }^{\circ} \mathrm{C}$ & ${ }^{\circ} \mathrm{C}$ & ${ }^{\circ} \mathrm{C}$ & ${ }^{\circ} \mathrm{C}$ \\
\hline 0.00 & 23.76 & 44.76 & 47.16 & 55.48 & 0.00 & 23.49 & 46.33 & 48.65 & 54.23 \\
\hline 0.07 & 23.73 & 46.52 & 49.16 & 54.06 & 0.14 & 23.45 & 48.03 & 50.54 & 52.77 \\
\hline 0.24 & 23.72 & 48.09 & 51.00 & 52.64 & 0.49 & 23.43 & 50.71 & 53.53 & 52.60 \\
\hline 0.50 & 23.70 & 49.99 & 53.18 & 51.57 & 1.04 & 23.44 & 54.48 & 57.78 & 53.85 \\
\hline 0.84 & 23.71 & 52.32 & 55.85 & 51.15 & 1.79 & 23.44 & 59.46 & 63.36 & 56.53 \\
\hline 1.27 & 23.71 & 54.80 & 58.77 & 51.21 & 2.71 & 23.44 & 64.93 & 69.52 & 60.02 \\
\hline 1.76 & 23.73 & 57.66 & 62.08 & 51.69 & 3.79 & 23.44 & 70.94 & 76.30 & 64.31 \\
\hline 2.33 & 23.73 & 60.25 & 65.10 & 52.50 & 5.01 & 23.45 & 77.19 & 83.42 & 69.21 \\
\hline 2.88 & 23.74 & 62.59 & 67.82 & 53.45 & 6.38 & 23.44 & 83.88 & 91.05 & 74.75 \\
\hline 3.51 & 23.74 & 66.38 & 72.23 & 55.01 & 7.81 & 23.47 & 90.55 & 98.91 & 80.76 \\
\hline 4.34 & 23.73 & 70.10 & 76.64 & 57.10 & 9.38 & 23.46 & 95.92 & 105.00 & 87.27 \\
\hline 5.17 & 23.74 & 74.10 & 81.34 & 59.46 & 11.08 & 23.45 & 100.78 & 112.00 & 94.31 \\
\hline 6.11 & 23.74 & 78.39 & 86.33 & 62.16 & & & & & \\
\hline 7.08 & 23.75 & 82.97 & 91.76 & 65.56 & & & & & \\
\hline 8.10 & 23.75 & 89.27 & 99.36 & 70.09 & & & & & \\
\hline
\end{tabular}


10 Advanced Computational Methods and Experiments in Heat Transfer XI

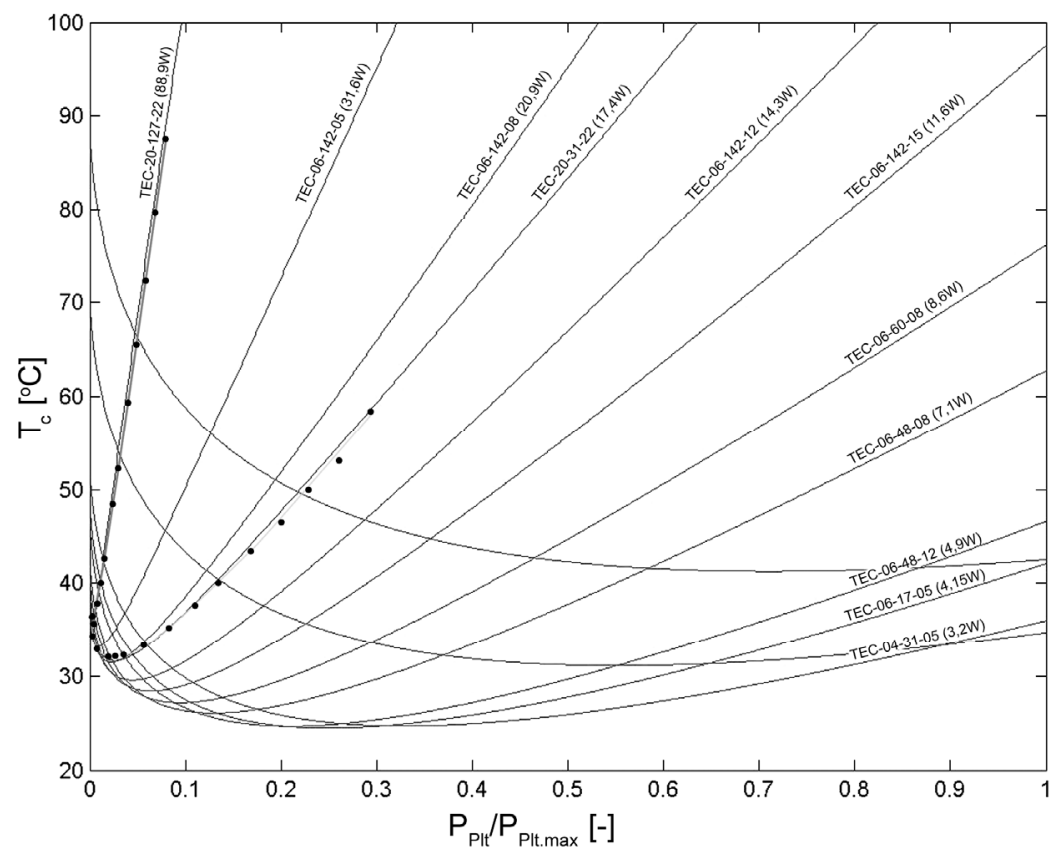

- $\quad$ Results of measurements

- Results of simulations

Figure 6: Results of measurements and simulations for LED power loss $P_{\text {thLed }}=1 \mathrm{~W}$.

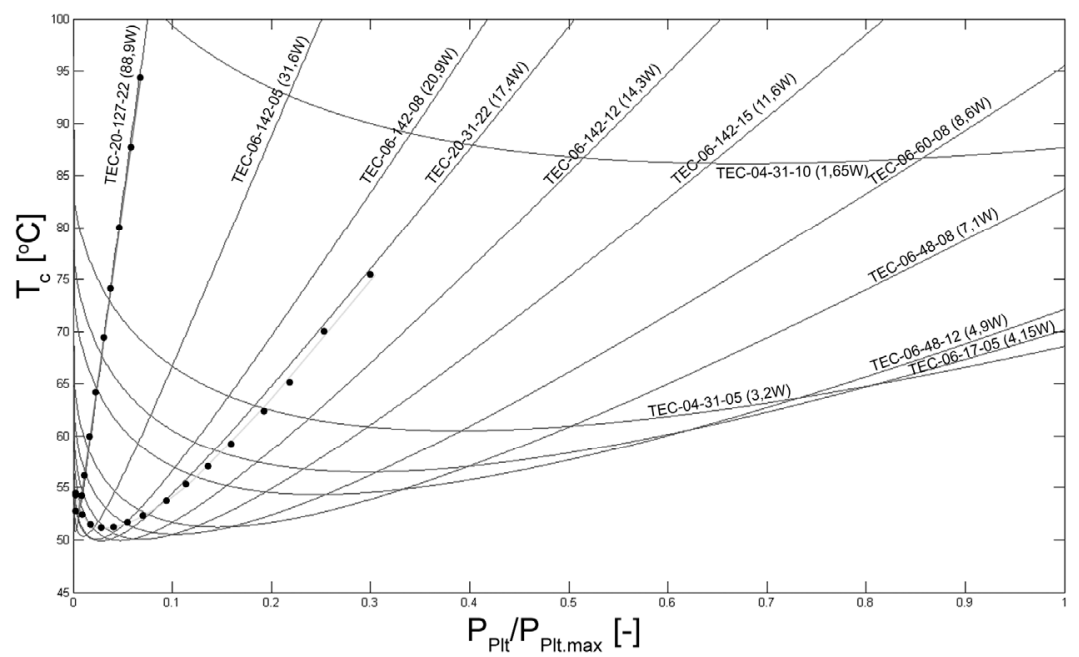

- Results of measurements $\quad-$ Results of simulations

Figure 7: Results of measurements and simulations for LED power loss $P_{\text {thLed }}=2.73 \mathrm{~W}$. 
To determine the remaining thermal resistances of the Peltier module, the following quantities were assumed [8]: $\lambda_{\text {Al2O3 }}=35\left[\mathrm{Wm}^{-1} \mathrm{~K}^{-1}\right]$ $\lambda_{\text {Air }}=0.026\left[\mathrm{Wm}^{-1} \mathrm{~K}^{-1}\right]$.

Additional thermal conductivities were also adopted for the system, resulting from the adverse effect of mechanical contacts between measurement surfaces of the cold and hot sides. The conductivities are defined as $R_{t h, o t h e r} \approx R_{t h, B i T e}$. Results of measurements are listed in Tables 1 and 2.

Measurements presented below, and results of numerical simulation, reveal a relationship between the temperature of the cooled element - the cold side of the $T_{c}$ module - and relative electrical power supplied to the $P_{P l t} / P_{P l t-\max }$ module for the test modules (cf. Fig. 6 and Fig. 7).

\section{Summary}

Results obtained in the study show that Peltier modules can be successfully applied in cooling systems of selected electronic components. Particularly suited are LEDs whose operating parameters deteriorate along with rising temperatures. Both simulations and experimental tests have demonstrated that Peltier module parameters for cooling systems require precise adjustment. An appropriate selection of parameters can produce a substantial reduction of temperature of the electronic element. In contrast, incorrectly selected parameters results in impaired heat dissipation and, consequently, increase the temperature of the electronic element. To ensure optimum selection, geometrical dimensions of the Peltier module should also be adjusted to the dimensions of the cooled element (LED), while the module's maximum refrigeration power and operating point must be appropriate for the thermal power carried away from the element, with due account taken of the potential for heat dissipation into the environment by the radiator. A comparison of the results of simulations and measurements performed in a test stand confirms that the assumed thermal model of the system is correct and, therefore, can be used as an alternative to the actual test stand for the determination of cooling system parameters.

\section{References}

[1] Rowe D.M.: Handbook of Thermoelectronics, CRC Press 1995.

[2] Rowe D.M.: Thermoelectronics Handbook - macro to nano, CRC Press 2006.

[3] Goldsmid H.J.: Introduction to Thermoelectricity, Springer 2009.

[4] Thermoelectric Technical Reference - http://www.ferrotec.com/technology/ thermoelectric/

[5] Domke K., Skrzypczak P.: Analiza cieplna układu: elektroluminiscencyjna dioda mocy - element Peltiera - radiator. (pol.) Przeglad Elektrotechniczny. nr 10, 2009, s.101-103

[6] Domke K., Skrzypczak P.: Dobór parametrów ogniwa Peltiera w układach chłodzenia diod elektroluminiscencyjnych dużej mocy. (pol.) XIV Konf. 
12 Advanced Computational Methods and Experiments in Heat Transfer XI

Nauk.-Techn. 'Zastosowania Komputerów w Elektrotechnice'. Mat., Poznań, 20-22.04.09, s. 333-334, 2008.

[7] Schubert E.F.: Lighting Emitting Diodes; Cambridge Univ. Press, 2006.

[8] Moulson A.J., Herbert J.M.: Electroceramics: Materials, Properties, Applications; John Wiley \& Sons Ltd 2003. 